This is the postprint version of my paper

Dietz, Gunther (2002): "On Rule Complexity. A Structural Approach". In: Foster-

Cohen, Susan H. \& Ruthenberg, Tanja \& Poschen, Marie Louise (Hg.): EUROSLA

Yearbook: Vol. 2, 263-286.

Page numberings of the original paper are marked by [264].

\title{
On rule complexity
} A structural approach

\section{Gunther Dietz}

University of Munich

\begin{abstract}
It is widely acknowledged by second language researchers that whether pedagogical rules should or can be explicitly taught is largely dependent on their complexity. Nevertheless, there is no consensus on what rule complexity exactly means. This paper first examines existing accounts of rule complexity and presents a conceptual analysis of the term 'rule'. It then proposes that 'complex' should not be equated with 'difficult', but used in a purely structural sense. Specifically a conditional formulation is proposed in which the number of concepts in the antecedent and the consequent, the number of subconditions, and the number of 'if-then' connections (subrules) within a given rule domain govern complexity. Finally, a classification of strategies of complexity reduction in foreign language pedagogy is sketched. Examples will be given from the field of German as a foreign language.
\end{abstract}

\section{Rule complexity in SLA research}

In the debate over the effectiveness of instruction and the usefulness of explicit teaching of grammar rules (see for example, Larsen-Freeman and Long 1991, Ellis 1994), it is interesting to note that whatever position is taken (non, weak or strong interface; selective attention, cf. Sharwood Smith 1993; Ellis 1994: 656), there has been agreement on the fact that rule complexity is a major factor affecting the learnability of target structures. A typical formulation is provided by Robinson (1996) who states,

It is possible that complexity affects structural noticing and rule understanding in the same why. Simply noticing the structures presented as examples is unlikely to be facilitative of learning if the structures themselves are too complex and the salient features of the structures that the rule regulates are consequently [264] not obvious. Similarly, the more complex the explanation of a rule is, the less likely 
it is to lead to understanding, and the more likely it is to be ignored in favour of simpler rules of thumb [...] (1996: 32; see also Robinson 1997: 225)

Indeed, 'complex' can be understood in either a psychological sense, i.e. as a synonym for 'hard, difficult to understand, explain, learn', or in a structural sense, i.e. as a synonym for 'put together, made up of closely connected parts'.

In most SLA studies 'complexity' has been used as a synonym for 'difficulty' and the proposals for criteria to define easy vs. hard rules include amongst others: abstractness/scope (Bialystok 1979), formal and functional simplicity (Krashen 1982; Ellis 1990), context dependence (Green and Hecht 1992), processing complexity (Pienemann 1989; 1998), difficulty of criteria (Dickerson 1990). ${ }^{1}$ However, in order to clearly distinguish between the psychological and the linguistic structural domains, 'difficult' will be used for the former and 'complex' for the latter.

To date, only two investigations have dealt with complexity as a structural feature of linguistic rules, namely Dickerson (1990) and Hulstijn and de Graaf (1994). In his analysis of the rule for pronouncing $\{Z\}$ and $\{D\}$ morphemes (i.e, the English plural, 3rd person singular present, and genitive marking, and past-tense, past participle and '-ed' adjective marking respectively), Dickerson (1990) points to various problems that beginning learners of English encounter when confronted with the traditional phonological based distributional rule:

Of all the morphemes that learners must use, only the $\{Z\}$ and $\{D\}$ morphemes have three allomorphs apiece to manage. In addition, management involves processes of making embedded phonological judgments of stem sounds. That is, the output of one decision, say sibilant versus nonsibilant, is the input to another decision, namely, voiced versus voiceless. Two-third of the forms in question attach to stems on the basis of second-level decisions. Complexity of this order is unparalleled in the rest of English suffixal morphology and poses a greater-than-ordinary cognitive challenge to learners." (p. 240/241.)

Dickerson thus sees complexity in 'the number of forms that must be manipulated and in the type of decisions that must be made' (p. 240). Note that the first criterion (number of forms) is a quantitative one, while the second (type of decisions) is a qualitative one.

Similarly, Hulstijn and de Graaff (1994) define complexity as follows:

Note that degree of complexity is contingent not so much on the number of forms in a paradigm, but rather on the number (and/or the type) of criteria to be applied in order to arrive at the correct form. (1994: 103) [265]

By 'number of criteria' the authors refer to the 'number of subcategories of a paradigm', and they give two (invented) examples to illustrate their point:

In language $M$, verbs have different endings for two aspects, perfect and non-perfect; in language $N$, however, verbs have different inflections for three aspects, perfective, durative, and punctual. In language $X$ there are two plural suffixes for nouns: the suffix $-s$ is added to singular nouns ending on a vowel, and the suffix - 
os is added to nouns ending on a consonant. Language $Y$ has the same two suffixes: -s for nouns ending on a vowel and for nouns ending on a consonant containing a front vowel in the penultimate syllable, -os for ending on a consonant and containing a back vowel in the penultimate syllable. (p. 102/103.)

Table 1: Examples for rule complexity based on Hulstijn and de Graaff (1994)

\begin{tabular}{|c|c|c|c|c|c|}
\hline \multicolumn{3}{|c|}{ Less complex } & \multicolumn{3}{|c|}{ More complex } \\
\hline$L_{M}$ & choi & between 2 aspect markers & $L_{N}$ & choice between 3 & ect markers \\
\hline \multirow[t]{2}{*}{ Lx } & - V & $\rightarrow-s$ & $L_{Y}$ & $\ldots \mathrm{V}+\ldots{ }^{*} \mathrm{~V}_{\text {front }}{ }^{*} \mathrm{C}$ & $\rightarrow-s$ \\
\hline & - C & $\rightarrow-\mathrm{OS}$ & & ${ }^{*} \mathrm{~V}_{\text {back }}{ }^{*} \mathrm{C}$ & $\rightarrow-\mathrm{OS}$ \\
\hline
\end{tabular}

Following this logic, schematised in Table $1, L_{M}$ and $L_{x}$ are less complex than $L_{N}$ and $L_{Y}$ respectively, because in $L_{N}$ the language user has to make a choice between three alternatives compared to only two in $L_{M}$, and in $L_{Y}$ not only the criterion of 'word ending' but additionally that of 'vowel quality in the penultimate syllable' has to be taken into consideration. Or, as Hulstijn and de Graaff put it: In $L_{M}$ and $L_{x}$ 'fewer steps in flow charts for the derivation of inflections' (1994: 103) are necessary. Note that in the definition cited above the type of criterion is being mentioned, although the authors do not go further into this.

The aim of the following sections will be to expand the sketch of structural complexity proposed by Dickerson and by Hulstijn and de Graaf because while it is intuitively plausible that some notion of 'quantity of information' affects the ease or difficulty of learning an L2 rule (in addition to qualitative factors such as abstractness, form-function opacity, and cue validity), one must examine those factors that might contribute to structural complexity before one can evaluate the effect of rule complexity on rule difficulty. [266]

\section{Terminological and conceptual issues}

Up to this point, the term 'rule' has been used in a rather vague fashion. However, on closer examination it can be seen that the term not only refers to a variety of different concepts, but is also used from different language processing perspectives. There is a variety of entities that can be referred to by the term 'rule', especially from the perspective of SLA research. ${ }^{2}$ Table 2 presents a survey of these concepts.

Table 2 suggests there are four basic senses of the term 'rule': rule as regularity, rule as a concrete formulation of such regularity, rule as a psychological entity, and rule as a structure indicating surface regularity. Each of these will be treated in turn. 
Table 2: Conceptual spectrum of 'rule'

\begin{tabular}{|c|c|c|}
\hline \multicolumn{2}{|c|}{ Concept } & \multirow[t]{2}{*}{ Label for concept } \\
\hline 1 & rule as a regularity that is inherent in language and/or language use & \\
\hline \multirow[t]{7}{*}{2} & rule as a concrete formulation of such a regularity, either as a(n) & \\
\hline & 2a scientific description of regularities in native speakers' language use & „linguist L1 rule” \\
\hline & $\begin{array}{l}\text { 2b scientific description of regularities in foreign language learners' lan- } \\
\text { guage use }\end{array}$ & „linguist interrule" \\
\hline & $\begin{array}{l}\text { 2c native speaker's explicit verbalization of his/her metalinguistic } \\
\text { knowledge }\end{array}$ & „reported L1 rule” \\
\hline & $2 d$ L2 learner's explicit verbalization of his/her metalinguistic knowledge & „reported interrule” \\
\hline & $2 \mathrm{e}$ instruction for native speakers how to use their language correctly & „pedagogic L1 rule” \\
\hline & $2 f$ instruction for $L 2$ learners how to use the target language correctly & $\begin{array}{l}\text { „pedagogic in- } \\
\text { terrule” }\end{array}$ \\
\hline \multirow[t]{3}{*}{3} & $\begin{array}{l}\text { rule as a psychological entity that is being activated during language pro- } \\
\text { cessing }\end{array}$ & „mental rule” \\
\hline & 3a in native speakers & „mental L1 rule” \\
\hline & $3 b$ in $L 2$ learners & „mental interrule” \\
\hline 4 & rule as a structure indicating the regularity on the surface of language. & \\
\hline
\end{tabular}

When the term 'rule' is used to refer to regularities inherent in language or [267] in language use, independent of their discovery and description by linguists or lay people, regularity can be thought of as the frequent appearance of a linguistic phenomenon under given circumstances, or as the frequent co-occurrence of at least two linguistic phenomena. Regularities can be discovered by analysing a given language as a system or by analysing the use of a given language by mature speakers or both. It must be noted, however, that neither the description of a subset of language facts nor whether they constitute a regularity are likely to be uncontentious in linguistics. Nevertheless, regularities can only be captured by concrete descriptions or formulations. These descriptions may differ from each other in many respects, depending by whom (e.g. experts vs. non-experts), for whom (e.g. linguists, natives vs. non-natives), with which goal (e.g. description vs. prescription/instruction) they are formulated and also by the degree of subjectivity (introspective vs. externally observed). The six subtypes of rule formulations mentioned above could in short be described as follows:

a. Linguist L1 rules is probably the most common understanding of the term rule. For many linguists the whole endeavour of linguistics can be described as discovering and describing the regularities of a specific language. 2a-type rules can therefore be found in any grammar handbook (scientific grammar) and in many linguistic publications.

b. Linguist interrules are also descriptions given by experts (linguists, SLA researchers) with the difference that it is not the regularities of native speakers' language use that are captured, but "rules describing the performance of IL users" (Færch, Haastrup and Phillipson 1984: 115). Within SLA research the importance of describing interlanguage rules began with the 
discovery that the transition from little knowledge of an L2 to possibly native-like use is not chaotic but can be described systematically as the development of their interlanguage (cf. Selinker 1972).

c. Reported L1 rules are rule formulations of non-expert native speakers elicited by linguists using some kind of introspective method (cf. Færch and Kasper 1987). These explicit statements of metalinguistic knowledge, besides using rather non-technical terminology, may or may not coincide with linguist L1 rules (see 2a) or with the informants actual linguistic performance.

d. Reported interrules are rule formulations of foreign language learners elicited by linguists or SLA researchers using some kind of introspective method. Such metalinguistic knowledge is one (but not the only) valuable source for tapping learners' interlanguage rules (2b). Reported interrules may not only differ from L1 rules (2a), but there may also be discrepancies between learners' explicit knowledge and actual performance (c.f. Seliger 1979, Green and [268] Hecht 1992, Dietz in press). It is therefore necessary to dissociate linguist interrules that are externally discovered by indirect methods of analysing performance data from reported interrules that are direct verbalisations of meta-knowledge. It is also obvious that learners can only report on interrules that are accessible to conscious introspection and therefore the number of reported interrules makes up only a fraction of the interrules actually used by learners. e. Pedagogic L1 rules are explicit rule formulations used by teachers and/or textbooks in order to instruct native speakers how to use their language correctly. Such rules are normally provided during school education, but due to the fact that an L1 is basically acquired without explicit rules or negative feedback, the domains of pedagogic L1 rules are predominantly in the area of literacy education, especially orthography.

f. Pedagogic interrules are explicit rule formulations used by foreign language teachers and/or textbooks in order to instruct language learners how to use the target language correctly. This didactic purpose imposes other design features for rule formulation as with linguist L1 rules (2a) (cf. Vogel and Vogel 1975, Berman 1979, Swan 1994, Westney 1994). Pedagogic interrules also differ from pedagogic L1 rules in terms of the range of domains: Normally far more domains of linguistic competence are formulated in rules for $L 2$ learners than for native speakers.

Often 'rule' is used to refer to the psycholinguistic / mental aspects of language knowledge or performance, i.e., to the rules of the mental grammar of mature speakers or learners $(3 a, 3 b){ }^{3}$ This presupposes that those rules that can be explicitly stated have some representation in cognitive structures or processing routines of language users, or in other words, that they are psychologically real. Whether symbolic rules are psychologically real or not is one of the major disputes within linguistics in the last decade (cf. Lima, Corrigan and Iverson 1994). Connectionist approaches in particular have suggested for an increasing range of phenomena that the observable behaviour of native or non-native speakers does not necessarily imply that they consciously or unconsciously apply rules. Connectionists think that symbolic rules are 
superfluous and they describe observable, rule-like, performance solely by processes of formfunction mapping. It therefore must remain open whether there is a mental representation of symbolic rules, and if so, for which areas of linguistic knowledge.

Finally, there is the use of the term 'rule' within SLA research in the sense of 'linguistic structure'. So, for example, 'plural-s' is referred to as an easy rule. This obviously is a metonymic use of the term 'rule' that conflates a surface phenomenon with the underlying regularity. A structure is just a part of a rule [269] expressed as a conditional: for production rules it is normally to be found in the consequent, for comprehension rules in the antecedent (see below). A structure may be more or less complex in linguistic terms, so one could argue that English 'plural-s' is not very complex, because it is a single monosyllabic morpheme affixed to a noun stem, while a structure such as the 'perfect tense' is more complex, because it consists of two separated parts (auxiliary + participle) and one of them has an inflectional alternation (have / has). It is probably this kind of complexity of structure that Krashen (1982: 97) and Ellis (1990: 166) had in mind when talking about 'formal simplicity'.

However, this discussion will not examine either the complexity of structures or the complexity of mental rules, but the structural complexity of the underlying regularities. As it is not possible to have direct access to regularities, for reasons mentioned above, the only way to grasp complexity is to analyse specific formulations of regularities. And among the six subgroups it is especially linguist L1 rules (2a) and pedagogic interrule (2f) that are of interest here: the first because they seem to come closest to describing exhaustively a regularity, and the second because it is these kind of rule formulations that learners are normally confronted with in formal instruction. Although there is likely to be dispute among experts about whether the chosen formulation of a regularity really is a good or descriptively adequate one, it is not my purpose here to argue for or against certain rule formulations. My concept of rule complexity can be made explicit on the assumption that the examples of rule formulations presented are at least one way to describe the regularity in question. With regards to pedagogic rule formulations (2f) one can expect that for didactic purposes teachers have intuitively or consciously established ways of reducing complexity for their students. This issue will be discussed further below.

\section{Rules for production and rules for comprehension}

By defining rules in terms of 'observed regularity with predictive value' (Westney 1994: 74) it is often neglected that rules do not describe regularities per se, but always from the perspective of language use, i.e. as either rules of production or rules of comprehension. The overwhelming number of rules found in grammar books are production rules. These can be divided into rules of use and rules of formation (cf. Westney 1994: 74). The former describe which structure a language user is to choose if $s$ /he wants to convey a certain meaning (function), while the latter describe the technical details of this structure. For example, if a [270] speaker 
wants to convey the meaning 'more than one', which is identical with 'plural' in English, a rule of use might be simply: 'If you refer to more than one entity, use plural marking', while a rule of formation would be stated as 'If you intend to use plural, add an -s to the noun. If the noun ends in a sibilant, use / $z /$, if it ends in a voiced non-sibilant, use / $z /$, if it ends in an unvoiced non-sibilant, use /s/'. While such a two-step description for production rules may not be realistic for first language acquirers or competent language users, the distinction between rules of formation and rules of use is indeed relevant for foreign language learning, simply because there might be form-function matches in the $L 2$ that differ from those in the $L 1$, thus there are two subtasks to be accomplished by the learner. In the case of plural marking the rule of use may not pose any problems, because in many languages of the world plurality is expressed by a marker on the noun. The complexity of the rule of formation, however, differs enormously between languages: In German, for example, one has to choose between eight different plural markers on the noun (Köpcke 1998: 307). So one can conclude that in order to get from (intended) meaning to (articulated) form, language learners are often confronted with a two-step-procedure: one which tells them which structure to use, and one which tells them how to use this structure.

Comprehension rules, on the other hand, have the following general format: 'If form A appears in context $C$, then it has to be interpreted as function $B^{\prime}$. For comprehension a division into two subtypes of rules could also be made. The equivalent for rules of formation would be something like rules of analysis, i.e. descriptions of how to interpret certain forms with respect to linguistic categorisations; while the equivalent of rules of use would be something like rules of interpretation, i.e. descriptions or instructions for how to interpret a linguistic categorisation with respect to its communicative function. With comprehension of plural, a rule of analysis has the format: 'If there is an -s at the end of a noun, categorise this noun as being plural,' while a rule of interpretation would be stated as: 'If a noun has a plural marker, interpret this noun with respect to number as "more than one"'. Nevertheless, it is not clear at all whether language learners do indeed need the same two-step-procedure for comprehension rules as for production rules. Intuitively, it seems that for comprehension there is a more straightforward way of getting from form to meaning than for production: something on the order of 'If there is an -s at the end of a noun, interpret this noun with respect to number as "more than one"'. Although this paper focuses only on production rules, it might be worthwhile to consider why, with respect to language learning, for comprehension rules a [271] one-step procedure is intuitively more adequate, while for production rules a two-step procedure makes more sense.

\section{A general format of rules}

In order to operationalise rule complexity in a linguistic-structural sense, it is important to use a format for rule formulations that can be used for all kinds of rules from different linguistic 
areas. Following linguistic (Zimmermann 1977, Fiehler 1995: 27 ff.) and psychological traditions (Gagné 1973) rules will be described in terms of conditional statements with a rule domain, antecedent ('if') clause and consequent. By rule domain is meant the linguistic phenomenon that is to be described by the rule. In a pragmatic sense it is the purpose of the rule. Examples for domains from different linguistic areas of German include the positioning of the finite verb in dependent clauses, how to open telephone conversations and the pronunciation of final consonants. Rule domains can be formulated at different levels of abstraction. For example, one could set up the rule domain 'word order' in German. However, since it is not possible to formulate a single rule that comprises all the information on word order regularities in German, this rule domain is too broadly defined for any descriptive or pedagogic purpose. On the other hand, 'inflection of weak nouns' in German would be too narrow a domain. While this domain may be relevant for foreign learners of German, it constitutes just a subdomain of the domain 'inflection of nouns' which from a communicative perspective is a more adequate level of domain formulation, because it best reflects the actual demands on language users; that is, to inflect any noun grammatically. Therefore, the regularities for weak nouns should be accounted for by a subrule within the domain 'inflection of nouns', and the abstract domain 'word order' should be split up into communicatively more adequate domains like 'positioning of verbs in subclauses', 'sequencing elements in the verbal complex' and so on.

In the antecedent (if clause) of the conditional statement, the input conditions are named under which a rule is to be applied. In the consequent (then clause) the result of the application of the rule, the output, is described. This conditional format can be justified from a psycholinguistic perspective: In the antecedent, the cues are named that trigger certain (mental) operations for reaching the communicative goal of the rule. For instance, in R1 below, a schwa in the final position of a singular noun functions as a cue for adding the morpheme $-n$, if the speaker wants to use a plural form (domain). [272]

(R1) a. $[N] \rightarrow<n>/ \ldots$ schwa

b. Nouns ending in schwa take $-n$ as their plural ending.

c. If a singular noun ends in schwa, it takes $-n$ as its plural ending.

d. If a singular noun ends in schwa, form its plural by adding $-n$.

With this conditional reading of the term 'rule' it is not important, whether the rule is a formula (R1a), a simple constative sentence (R1b), a conditional constative sentence (R1c), or a conditional imperative sentence (R1d). The crucial point is that the antecedent and consequent can be clearly identified. ${ }^{4}$

\section{Complexity as a structural feature of rules}

Based on the general format of linguistic rules presented above, complexity can now be operationalised as (a) the number of criteria appearing in the antecedent and the consequent respectively (b) the number of subconditions within a conditional rule statement, and (c) the 
number of 'if-then' connections (subrules) necessary to account for the domain in question. Note that with this approach the Hulstijn and de Graaff criterion 'number (and/or the type) of criteria to be applied in order to arrive at the correct form' is regarded as important, but not sufficient, because it does not take into consideration the internal structuring of a rule formulation. That is, it makes no difference whether the concepts appear in the antecedent or in the consequent, and whether the regularity can be described by one, or by more than one subrule. In what follows, these three factors of complexity will be illustrated with examples from scientific and pedagogic grammars of German.

The criteria which contribute to rule complexity are the relevant units of information that specify the antecedent and/or consequent of a rule. Figure 1 shows a schema for rules with a varying number of criteria. In this and subsequent figures, the following abbreviations are used to denote elements of rules in the examples: ' $C D$ ' for the antecedent of the conditional rule, 'CS' for the consequent, 'CDa \& CDb ...' for criteria within the antecedent of the conditional (logical and), 'CSa \& CSb ...' for criteria in the consequent (logical and), 'CD1 + CD2 ...' for listed subconditions (logical or), 'SR1, SR2 ...' for subrules, and '< ... >' for domains.

Fig.1: Scheme for rules with a varying number of criteria

$$
\mathrm{CD}(\mathrm{a} \& \mathrm{~b} \& \mathrm{x}) \quad \rightarrow \quad \mathrm{CS}(\mathrm{a} \& \mathrm{~B} \& \mathrm{x})
$$

In the antecedent of a rule like R1 (see above), the criteria 'ending' and 'schwa' appear, while the consequent is specified by the plural ending -en. In this case, there are only a few criteria to be applied. In other cases learners have [273] to apply more criteria simultaneously, as in R2 below where the antecedent contains two criteria ('indicative', and 'with regular verbs') and the consequent has three criteria: 'stem', 'personal ending' and the morpheme -te.

(R2) Der Indikativ des Präteritums wird bei regelmäßigen Verben gebildet, in dem zwischen Stamm und Personalendung ein -te- eingefügt wird. (Helbig and Buscha 1986: 27) $<$ Unterregel zur Bildung des Präteritums>

With regular verbs the indicative of the preterite is formed by inserting -te- between the stem and the personal ending.

<subrule for preterite formation>

In principle, a variety of entities can be subsumed under the notion of 'criterion', ranging from non-technical concepts (e.g., 'insert', 'add', 'separate') to exemplars of a paradigm (specific sounds, morphemes, lexemes etc.) to linguistic classificatory terms ('morpheme', 'ending', 'irregular verb', 'preterite') to abstract relational concepts ('perfective', 'agreement' etc.).

Complexity can also be increased by increasing the number of subconditions. Subconditions are sets of criteria embedded in the antecedent of a single consequent. Figure 2 provides a schema for rules with a list of subconditions. 
Fig.2: Scheme for rules with a list of subconditions

$$
\mathrm{CD} 1(\mathrm{a} \ldots \mathrm{x})+\mathrm{CD} 2(\mathrm{a} \ldots \mathrm{x})+\mathrm{CDn} \quad \rightarrow \quad \mathrm{CS}
$$

In R3, below, for instance, there are two subconditions: 'masculine nouns ending in $-e$ ' and 'feminine nouns'; while R4, describing devoicing (Auslautverhärtung) in German, contains information on the two subclasses of sounds that are affected by the rule, namely voiced stops and voiced fricatives, and their specific position (here: coda). However, there are also rules, like R5, that contain considerably more subconditions: According to the grammar handbook of Helbig and Buscha (1986), there are six subconditions for the use of haben and four for sein as an auxiliary verb in the formation of the 'Perfekt' and 'Plusquamperfekt' tenses in German.

(R3) Maskulina, die auf -e enden (CD1) und Feminina (CD2) bilden den Plural auf -en bzw. auf -n (CS) [...]. (Drosdowski 1995: 229)

$<$ Unterregel zur Pluralbildung>

Masculine nouns ending in - $e(C D 1)$, and feminine nouns (CD2) take -en or $-n$ respectively as plural ending (CS) [...]. <subrule for plural formation>

(R4) Im Silben-Endrand werden stimmhafte Verschluss- (CD1) und Reibelaute (CD2) stimmlos (CS) gesprochen.

$<$ Aussprache von Konsonanten im Silben-Endrand>

In coda position voiced stops (CD1) and voiced fricatives (CD2) become voiceless (CS) <pronunciation of consonants in coda position>

(R5) Haben (SR1/CS) wird zur Bildung der Vergangenheitsformen benutzt:

1. bei den transitiven Verben [...] (SR1/CD1)

2. bei den Mittelverben [...] (SR1/CD2)

3. bei allen reflexiven Verben [...] (SR1/CD3)

4. bei allen Modalverben [...] (SR1/CD4)

5. bei den unpersönlichen Verben [...] (SR1/CD5)

6. bei intransitiven Verben von durativer Aktionsart [...] (SR1/CD6)

Sein (SR2/CS) wird zur Bildung der Vergangenheitsformen benutzt:

1. bei intransitiven Verben von perfektiver Aktionsart [...] (SR2/CD1)

2. bei allen Verben der Bewegung, die eine Ortsveränderung bezeichnen: [...] (SR2/CD2)

3. bei den Verben sein und bleiben (obwohl sie intransitiv und durativ sind): [...] (SR2/CD3)

4. bei einigen wenigen zusammengesetzten oder abgeleiteten transitiven Ver ben, deren Stamm die Vergangenheitsform mit sein bildet: [...] (SR2/CD4) (Helbig and Buscha 1986: 137-140).

Haben (SR1/CS) is used for perfect tense formation

1. with transitive verbs, $[. .$.$] (SR1/CD1)$

2. with Mittelverben, [...] (SR1/CD2)

3. with all reflective verbs, $[\ldots]$ (SR1/CD3) 
4. with all modal verbs, $[\ldots]$ (SR1/CD4)

5. with impersonal verbs, [...] (SR1/CD5)

6. with intransitive verbs of durative aspect [...] (SR1/CD6).

Sein (SR2/CS) is used for perfect tense formation

1. with intransitive verbs of perfective aspect (SR2/CD1) [275]

2. with all verbs of movement referring to change of position (SR2/CD2)

3. with the verbs sein ('be') and bleiben ('stay'), even though they are intransi tive and durative; (SR2/CD3)

4. with some few compound or derived transitive verbs, the word stem of which forms its perfect tense with sein (SR2/CD4).

Turning now to the complexity contributed by the number of subrules, we can understand subrules to be antecedent-consequent connections that are necessary to describe the domain in question. With this type of complexity, the choice of consequents comes into play. That is, to achieve a specific communicative purpose, speakers have to choose between two or more consequents, each of them being specified by their antecedents. This is obviously the kind of complexity Hulstijn and de Graaff had in mind with the example of aspect marking discussed above.

The simplest subrule case is where there is one antecedent condition and only one consequent as in R4 above, or R6 below (a rule of Hungarian) where the antecedent is only specified by immer 'always', i.e. the consequent applies to all words. In this case, it does not see appropriate to even talk in terms of subrules.

(R6) Der Wortakzent liegt immer (CD) auf der ersten Silbe des Wortes (CS). $<$ Positionierung des Wortakzents im Ungarischen>

Word stress always (CD) lies on the first syllable of a word (CS). $<$ positioning of word stress in Hungarian>

However, on closer examination, these rules can be seen as implicitly conveying regularities with two or more alternatives, since they state a regularity against the background of assumed regularities: In the case of R4 with its domain 'pronunciation of consonant sounds in coda position' devoicing is explicitly stated and thus highlighted, while there are several other rules (or, rather, subrules) which do not have to be stated explicitly, i.e. that voiced sounds other than stops and fricatives (like nasal sounds $\{m, n\}$ ) are by default not pronounced as voiceless sounds in coda position and so on. The only reason why in R6 no subrules are necessary lies in the fact that this rule applies categorically to all words. Therefore, possible other subrules with consequents like stress on the last or on the penultimate syllable, are in this special case ruled out.

More often speakers have to make an explicit decision between two or more alternative subrules in order to reach their communicative goal. Within rule domains with two subrules, we can distinguish between rules where the choice [276] is between doing or not doing 
something (binary rules), and rules where there are two autonomous alternatives (dichotomous rules).

Table 3: Examples for binary rule domains in German

\begin{tabular}{lll}
\hline Field & Domain & Consequences \\
\hline O & comma setting & comma vs. no comma \\
O & spelling of multiple-lexeme words & separate vs. not separate \\
MS & passivization of verbs & can vs. cannot be put into passive voice \\
MS & separability of prefix verbs & separable vs. not separable \\
MS & use of infinitive after infinitive verbs & with vs. without $z u$ \\
\hline
\end{tabular}

Some examples of binary rule domains are listed in Table 3 where ' $O$ ' stands for 'orthography', 'MS' for 'morpho-syntax', 'Prg' for 'pragmatics', 'Pho' for 'phonetics' and 'Wo' for 'word order'. A schema for binary rules is provided in Figure 3.

Fig. 3: Scheme for binary rules

\begin{tabular}{|lll|}
\hline $\mathrm{SR} 1 / \mathrm{CD}$ & $\rightarrow$ & $\mathrm{SR} 1 / \mathrm{CS}$ \\
$\mathrm{SR} 2 / \mathrm{CD}$ & $\rightarrow$ & non SR1/CS \\
\hline
\end{tabular}

In line with Table 3 certain conjunctions (aber, sondern) are obligatorily followed by a comma, while with others (und, oder) a comma is forbidden or optional. According to R7 below, some German prefix verbs have to be separated in the present (and other) tenses, as in the case of einkaufen 'to shop' (Er kauft heute ein. 'He's going shopping today.'), while other prefix verbs must not be split, as in the case of verkaufen 'to sell' (Er verkauft heute sein Auto 'He's selling his car today'). The conditions for separability are stress on the prefix vs. no stress on the prefix, respectively.

(R7) Als allgemeine Regel kann gelten, daß betonter erster Teil trennbar, unbetonter erster Teil dagegen untrennbar ist. (Helbig and Buscha 1986: 222)

$<$ Trennbarkeit von Verbpräfixen>

As a general rule, stressed first parts [of verbs, GD] are separable, unstressed first parts are not separable.

<separability of verb prefixes> [277]

Dichotomous rules, on the other hand, contain two subrules with qualitatively different consequences as shown in the schema in Figure 4.

Fig. 4: Scheme for dichotomous rules

\begin{tabular}{|lll|}
\hline $\mathrm{SR} 1 / \mathrm{CD}$ & $\rightarrow$ & $\mathrm{SR} 1 / \mathrm{CS}$ \\
$\mathrm{SR} 2 / \mathrm{CD}$ & $\rightarrow$ & $\mathrm{SR} 2 / \mathrm{CS}$ \\
\hline
\end{tabular}

Thus, speakers have to choose between haben or sein as an auxiliary verb in 'Perfekt' formation; they have to use aber or sondern as an adversative conjunction; they have to use the 
$d u$ paradigm or the Sie paradigm for addressing people, and so forth. Examples of dichotomous rule domains in German are presented in Table 4.

Table4: Examples for dichotomous rule domains in German

\begin{tabular}{lll}
\hline Field & Domain & Consequences \\
\hline O & spelling of $s s / \beta$ & ss vs. $\beta$ \\
MS & formation of subjunctive II & $\begin{array}{l}\text { synthetic vs. analytic (würde + infini- } \\
\text { tive) }\end{array}$ \\
& & haben vs. sein \\
MS & formation of analytic tenses (perfect, past perfect) & aber vs. sondern \\
MS & selection of adversative conjunctions & wenn vs. als \\
MS & selection of temporal conjunctions & damit vs. um ... zu \\
MS & selection of final conjunctions & wie vs. als \\
MS & selection of comparative conjunctions & preposition + article vs. wo $(r)-+$ prep- \\
MS & selection of relative conjunction & osition \\
& & sollen vs. müssen \\
MS & selection of modal verb to express „necessity” & accusative vs. dative \\
MS & selection of case after „either-or” prepositions & nicht vs. kein- \\
MS & selection of negator with negated NPs & $d u$ vs. Sie \\
Prg & forms of address &
\end{tabular}

As they both consist of two subrules, there is no difference between binary and dichotomous rules with respect to the complexity criterion of the number of subrules. They do differ, however, in that with binary rules the two consequents are qualitatively not different from each other while with dichotomous rules they are. It is hard to say whether this particular feature has any influence [278] on the ease/difficulty of applying these two subtypes of rules. Complexity within binary and dichotomous rules predominantly arises from the number of subconditions (see above). Thus, at the least complex end of the scale are rules with one condition in each of the subrules. These are rules with a clear-cut complementary distribution of the consequents, such as the 'a/an'alternation in English (shown in R8) or, just slightly more complex, the rule for $s s / \beta$-alternation following the reformed spelling rules of German (shown in R9). In subrule 1 of R9 there are two subconditions ('after long vowel', 'after diphthong'). At the other end of the complexity scale are dichotomous rules with a considerable number of subconditions like those for auxiliary selection for perfect tense formation (R5 above).

(R8) A (SR1/CS) is used before consonant sounds [...] (SR1/CD), an (SR2/CS) is used before vowel sounds [...] (SR2/CD2). (Alexander 1988: 57)

<selection of 'a' vs. 'an' as indefinite article>

(R9) Man schreibt $\beta$ (SR1/CS) für den in allen Beugungsformen stimmlosen s-Laut nach langem Vokal (Selbstlaut) (SR1/CD1) oder nach Doppellaut (Diphthong) (SR1/CD2) [...]. Man schreibt ss (SR2/CS) für den stimmlosen s-Laut nach kurzem Vokal (SR2/CD). (Dudenredaktion 1995: 58)

<Orthographieregel für Schreibung des stimmlosen s> 
$\beta$ (SR1/CS) is written for voiceless s after long vowels (SR1/CD1) or after diphthongs (SR1/CD2) [...]. ss (SR2/CS) is written for voiceless $s$ after short vowels (SR2/CD) [...] $<$ spelling rule for voiceless $s$-sound>

Finally, multiple rules are those with more than two subrules to cover the domain as shown in the schema in Figure 5.

Fig.5: Scheme for multiple rules

\begin{tabular}{|lll|}
\hline $\mathrm{SR} 1 / C D$ & $\rightarrow$ & $\mathrm{SR} 1 / \mathrm{CS}$ \\
$\mathrm{SR} 2 / \mathrm{CD}$ & $\rightarrow$ & $\mathrm{SR} 2 / \mathrm{CS}$ \\
$\mathrm{SR} 3 / \mathrm{CD}$ & $\rightarrow$ & $\mathrm{SR} 3 / \mathrm{CS}$ \\
$\mathrm{SR} 4 / \mathrm{CD}$ & $\rightarrow$ & $\mathrm{SR} 4 / \mathrm{CS}$ \\
$\ldots$ & $\rightarrow$ & $\ldots$ \\
\hline
\end{tabular}

Multiple rules may consist of three subrules as shown in R10 or R11, or they may consist of a considerably greater number of subrules. Thus, in German there are at least five ways to pronounce the 'ch' letter combination, five ways to mark genitive case on the noun, and eight ways to mark plurality on nouns. Table 5 provides examples of multiple rule domains in German.

Table 5: Examples for multiple rule domains in German (ordered by number of subrules)

\begin{tabular}{|c|c|c|c|}
\hline Field & Domain & Consequences & SR \\
\hline Pho & position of word stress & prefix vs. stem vs. suffix & 3 \\
\hline Pho & pronunciation of letter combination $<\mathrm{ng}\rangle$ & [n] vs. [ng] vs. [ng] & \\
\hline MS & gender selection & fem. vs. masc. vs. neutr. & \\
\hline MS & $\begin{array}{l}\text { selection of NP case after verbs with preposi- } \\
\text { tional complements }\end{array}$ & acc. vs. dat. vs. gen. & \\
\hline MS & selection of article & def. vs. indef. vs. zero article & \\
\hline MS & selection of inflectional class with adjectives & „strong” vs. „weak” vs. „mixed” & \\
\hline Wo & $\begin{array}{l}\text { positioning of the finite verb in subordinate } \\
\text { clauses }\end{array}$ & „first” vs. „second” vs. final & \\
\hline MS & selection of verb flexives for present tense & $-e$ vs. $-s t$ vs. $-t$ vs. $-e n$ & 4 \\
\hline Pho & pronunciation of letter combination $<\mathrm{ch}>$ & $[\mathrm{x}]$ vs. [ç] vs. [J] vs. [t] $]$ vs. [k] & 5 \\
\hline MS & selection of genitive marker at the noun & -s vs. -es vs. - $n$ vs. -en vs. $\varnothing$ & \\
\hline MS & $\begin{array}{l}\text { selection of adjective endings of the 'strong' } \\
\text { declension }\end{array}$ & -ervs. -e vs. -en vs. -es vs. -em & \\
\hline MS & plural marker selection & $\begin{array}{l}-e \text { vs. }-(e) n \text { vs. }-\varnothing \text { vs. -er vs. -s vs. -"e } \\
\text { vs. - Ø vs. -"e }\end{array}$ & 8 \\
\hline
\end{tabular}

One might object here that in these examples of multiple rules some of the subrules are very infrequent, that for instance ' $c h$ ' is pronounced [ $\left.\int\right]$ only in some loan words like Champagner 'champagne' while in the overwhelming majority of contexts there is simply a dichotomous choice between [ç] as in dich 'you-ACC' and [x] as in Dach 'roof'. Nevertheless, this objection 
is not valid at this [279] point of my argumentation. Frequency considerations will come into play below in the discussion of strategies for reducing complexity for pedagogic purposes. [280]

(R10) In eingeleiteten (SR1/CD) Nebensätzen steht das finite Verb am Satzende (SR1/CS). [...] In nachgestellten (SR2/CDa) uneingeleiteten (SR2/CDb) Nebensätzen steht das Verb an zweiter Stelle (SR2/CS), in vorangestellten (SR3/CDa) an erster Stelle (SR3/CS). (Hall and Scheiner 1997: 270)

<Stellung des finiten Verbs in Nebensätzen>

When subordinate clauses are introduced (by a conjunction, GD) (SR1/CD), the finite verb goes to the end of the clause (SR1/CS). [...] With postposed (SR2/CDa) subordinate clauses not introduced (by a conjunction, GD) (SR2/CDb) the verb is at the second position (SR2/CS), with preposed (SR3/CDa) subordinate clauses not introduced (by a conjunction, GD), the verb is at first position (SR3/CS). <positioning of the finite verb in subordinate clauses>

(R11) Die Buchstabenkombination <ng> wird in einheimischen deutschen Wörtern (SR1/CD) als ein Laut gesprochen, und zwar als [ $\eta]$ (SR1/CS), an Morphem-Grenzen (SR2/CD) jedoch als zwei Laute, nämlich [ng] (SR2/CS). In Fremdwörtern (SR3/CD) wird $<n g>$ wie im Ungarischen als [ng] realisiert (SR3/CS). (Dietz and Tronka 2001: 172)

$<$ Aussprache der Buchstabenkombination ' $n g$ '>

The letter combination <ng> is pronounced as one sound, i.e. as [ $\mathrm{y}$ ] (SR1/CS), in native German words (SR1/CD), but at morpheme boundaries (SR2/CD) as two sounds, namely [ng] (SR2/CS). In foreign words $(S R 3 / C D)<n g>$ is pronounced like in Hungarian as [ng] (SR3/CS).

<pronunciation of letter combination ' $n g$ '>

\section{On the difficulty of rule learning}

In the model proposed above there are three factors that contribute to rule complexity: the number of criteria, the number of subconditions, and the number of subrules. The next question to ask is how these factors contribute to the ease or difficulty of learning these rules in the sense of understanding its application in communicative tasks (as opposed to learning the wording of the rules themselves (cf. Gagné 1973: 121)). It is at first sight persuasive to state that the more criteria or concepts appear in a rule the more processing work the learner has to do. It might be that if learners have to give attention to a considerable number of criteria in order to apply the rule correctly, they might more easily forget relevant information or confuse criteria, especially when they are spread over several subconditions and/or subrules. However, the mere number [281] of criteria is unlikely to contribute linearly to processing complexity, because the type of concept also affects ease of rule application (De Graff 1997:251). For example, the number of criteria in a rule formulation like R4 varies with the degree of abstractness of the terms used in the antecedent. The reformulation of R4 below presents it in its more expanded form in which all the alternatives are spelled out in terms of 
whether the rule applies to an abstract linguistic term like 'obstruents' (R4a), hyponyms of such as 'plosives' and 'fricatives' (R4b), or exemplars of the sounds in question (R4c).

(R4) a. Voiced obstruents become voiceless in coda position.

b. Voiced plosives and fricatives become voiceless in coda position.

c. The consonants $\{b, d, g, v, z\}$ become voiceless in coda position.

(R4a) may be the shortest and most precise formulation for linguists, but the reduced complexity achieved presumably will not help learners a great deal, even if they know what the term 'obstruent' means. In other words: low complexity in the sense of number of concepts may combine with high abstractness, and in order to formulate a pedagogical rule, it might be better to use the more common terms 'plosive' and 'fricative' or even list the five concrete exemplars of sounds (R4c).

The number of subconditions of (sub) rules is likely to be relevant for processing difficulty. The more subconditions a learner has to memorise in order to reach her/his communicative goal the higher the risk of confusing the consequents. However, the number of subrules, is likely to have the greatest impact on processing difficulty. The need to select between three or more alternatives in order to arrive at the correct form, the checking which of the subrules applies, seems to require a greater mental effort than in cases where there are no, or just two, alternatives.

\section{Pedagogic strategies to reduce structural complexity}

In language pedagogy a variety of strategies have been developed to reduce structural complexity. As mentioned above, reducing the number of criteria by using more abstract concepts may lead to a structurally less complex rule, but the cost of this reduction might be too high for learners, because the abstractness of the terms used may conflict with the pedagogic demand to present criteria that are easily understood and detected by learners. On the other hand, reduction of number of criteria takes place as a side-effect of reducing the [282] number of subconditions and reducing the number of subrules.

Candidates for omission in pedagogic rules are subconditions and subrules of low reliability and/or restricted scope. R1 above has a high reliability (about 96\%), as there are only 6 exceptions, where nouns ending in schwa do not end in $-n$, namely some neuter nouns of the morphological structure Ge- + stem + -e like Gebirge 'mountains'. The scope of R1, on the other hand, is the number of singular nouns ending in schwa divided by the number of all other singular nouns. According to the data presented by Mugdan (1977: 101), this amounts to $20.4 \%$ of basic vocabulary. In other words: although this rule is very reliable, it applies only to one fifth of all nouns (as types). One can assume that the availability of reliability and scope data is relevant for the decision to teach a subrule at all or at least to evaluate the usefulness of a subrule (see Hulstijn and de Graaff 1994 and Hulstijn 1995 for a more extended discussion of scope and reliability). 
Another way of reducing the number of subrules could be labelled the 'if-otherwise' strategy. It can be formulated as 'Check whether the conditions for the marked subrule hold. If they do, apply this rule, otherwise apply the default subrule.' For example, instead of listing both subrules with 10 subconditions for haben/sein selection, there is an enormous reduction of complexity to be had by using the following instruction format:

(R12) Check whether the verb in question belongs to one of the three sein groups. If it does, use sein for Perfekt tense formation, otherwise use haben.

A final strategy that might be mentioned can be called the 'weighting subrules' strategy. Here one out of two or more subrules is considered as the major rule, while the others are minor rules. Major rules thus may have the status of 'rules of thumb' (Berman 1979, Færch 1986), while minor rules can either be refinements of the major rule, i.e. further specifications of the major rule for special cases, or may contain exceptions to the major rule. In either case, one subrule, usually that of widest scope and highest reliability, is focussed on for pedagogical purposes.

To summarise, the question of how much the complexity of a rule / regularity can or should be reduced for pedagogical purposes, can at least partly be answered by taking into consideration other quantitative factors, particularly reliability and scope. Unfortunately for many phenomena corpus linguistic quantitative data are missing, or if they exist, they are not noticed by teachers or textbook authors. [283]

\section{Conclusion}

This paper has attempted to examine the notion of structural complexity, which seldom and then only very vaguely has been operationalised in the literature. To this end, it has attempted to formulate some hypotheses about how structural complexity may be linked to psychological difficulty experienced by learners. However, even if one accepts the description of rule complexity sketched above many questions remain to be solved.

The first and most obvious of these is whether there is any empirical evidence that the complexity criteria proposed are actually relevant for processing rules. Relevant data might come from reanalysing known problematic target language structures identified by learners, teachers or researchers, on the assumption that particularly resistant errors are those in more complex structures as measured here, while easier structures rely on less complex rules. Such rankings are themselves problematic but may still be the only non-experimental evidence of experienced difficulty (cf. Robinson 1996 for English, Serra Borneto 2000 for German). Alternatively, one could seek experimental data by presenting two different sets of rules for the same rule domain, with one rule being more complex (in terms of the criteria proposed here) than the other, and observe how learners respond to them. Probably the use of artificial language experiments similar to those used by DeKeyser (1995), N. Ellis and Schmidt (1997), or 
de Graaff (1997) is a more appropriate way to control for differences in complexity than by using natural language material.

A second issue concerns the weight of the criterion of structural complexity as compared with other criteria for rule difficulty such as abstractness, functional complexity (form-meaning connections), context dependence, detectability of cues, scope, reliability, L1 contrasts and so on. Here it is necessary to analyse the demands of pedagogic rules on learners in general but also on specific groups of learners. Qualitative criteria for evaluating rule difficulty might include the familiarity of the learners with the concepts appearing in a rule (Do learners know what is referred to by terms used in pedagogic rules (intentional knowledge)? Are they able to classify given lexemes to these concepts (extensional knowledge)); the strength (detectability) of cues in the condition parts of rules (Can learners easily detect the signals / cues that trigger them to apply a rule? Are these cues always there? (cf. Dickerson 1990; Dietz 2001a)); the implicativeness of rules (Are the decisions to be made by learners based on the knowledge of other rules? Can learners be expected to know these rules? (Dietz 2001a)).

As a final remark, it must be emphasised that the claim here is not that [284] learners acquire the regularities of a foreign language solely through explicit rule learning. Clearly, learners also engage in implicit learning (N. Ellis and Schmidt 1997, Kempe and MacWhinney 1998, Hulstijn in press), and it may turn out that regularities with a high degree of complexity in the structural sense proposed here are good candidates for implicit learning.

\section{Notes}

1. For an overview see e.g. Doughty and Williams (1998: 221-226) and Dietz (2001b).

2. This classification is only partly identical with those by Færch, Haastrup and Phillipson (1984: 114f.) or Zimmermann (1977: 116). It also draws upon different meanings of the term grammar proposed by Helbig (1993: 21). For alternative conceptual analyses of 'rule' see Westney (1994) and Sharwood Smith (1994).

3. With respect to L2 learners, Zimmermann (1977: 116; my translation, GD) speaks of „internalised rules that - in part or in total unconsciously - control a learner's language behaviour".

4. Sharwood Smith (1994) makes a distinction between an instruction and a principle format of rules.

\section{References}

Alexander, L.G. 1988. Longman English Grammar. London and New York: Longman.

Berman, R.A. 1979. „Rule of grammar or rule of thumb?”. International Review of Applied Linguistics 27 (4): 279-302.

Bialystok, E. 1979. „Explicit and implicit judgements of L2 grammaticality”. Language Learning 29: 81-103. 
de Graaff, R. 1997. „The eXperanto experiment. Effects of Explicit Instruction on Second Language Acquisition". Studies in Second Language Acquisition 19: 249-276.

DeKeyser, R.M. 1995. „Learning second language grammar rules: An experiment with a miniature linguistic system". Studies in Second Language Acquisition 17: 379-410.

Dickerson, W.B. 1990. „Morphology via Orthography: A Visual Approach to Oral Decisions”. Applied Linguistics 11 (3): 238-252.

Dietz, G. 2001a. „Warum sind sprachliche Regeln schwer? Versuch über den Operationalisierbarkeitsbegriff". [in Online-Ergänzungsdokumentation des DGFF-Kongresses 1999; http://www.dgff.de/publ-dietz.html].

Dietz, G. 2001b. „Miért nehezek a nyelvi szabályak? Egy kutatási puzzle részei” [Why are linguistic rules difficult? Fragments of a research puzzle]. In A nyelvtantól a szövegtanig. Tanulmányok Kocsány Piroska tiszteletére, P. Csatár, P. Maitz and K. Tronka (eds.), 2947. Debrecen: Kossuth Egyetemi Kiadó. [285]

Dietz, G. in press. „Selektion von Pluralmarkern bei ungarischen Deutschlernern - eine retrospektive Untersuchung". (to appear in Zeitschrift für Fremdsprachenforschung 2002)

Dietz, G. and Tronka, K. 2001. SprechProbe. Aussprachetraining für ungarische DaF-Lerner. Arbeitsbuch. Debrecen: Kossuth Kiadó.

Doughty, C. and Williams, J. 1998. „Pedagogical choices in focus on form”. In Focus on form in classroom second language acquisition, C. Doughty and J. Williams (eds.), 197-261. New York: Cambridge UP.

Drosdowski, G. (ed.) 1995. DUDEN Grammatik der deutschen Gegenwartssprache. 5th ed. Mannheim: Dudenverlag (DUDEN Bd. 4).

Dudenredaktion (ed.) 1995. DUDEN Rechtschreibung der deutschen Sprache. 21st ed. Mannheim, Leipzig, Wien, Zürich: Dudenverlag.

Ellis, N.C. and Schmidt, R. 1997. „Morphology and Longer Distance Dependencies. Laboratory Research Illuminating the A in SLA". Studies in Second Language Acquisition 19: 145-171.

Ellis, R. 1990. Instructed Second Language Acquisition. Oxford: Blackwell.

Ellis, R. 1994. The Study of Second Language Acquisition. Oxford u.a.: Oxford University Press.

Færch, C. 1986. „Rules of Thumb and other Teacher-formulated Rules in the Foreign Language Classroom". In Teaching and Communication in the Foreign Language Classroom Learning, G. Kasper (ed.), 125-143. Aarhus: Aarhus UP.

Færch, C. and Kasper, G. (ed.) 1987. Introspection in Second Language Research. Clevedon: Multilingual Matters (Multilingual Matters 30).

Færch, C. and Haastrup, K. and Phillipson, R. 1984. Learner Language and Language Learning. Clevedon: Multilingual Matters.

Fiehler, R. 1995. „Weichenstellungen der Sprachwissenschaft und ihre Folgen oder: Zum Verhältnis von Grammatik und Pragmatik". In Sprache als Kognition - Sprache als Interaktion. Studien zum Grammatik-Pragmatik-Verhältnis. A. Kertész (ed.), 19-58. Frankfurt/Main et. al.: Lang [MetaLinguistica 1].

Gagné, R.M. 1973. Die Bedingungen des menschlichen Lernens. 3. Aufl. Hannover: Schroedel.

Green, P.S. and Hecht, K. 1992. „Implicit and Explicit Grammar: An Empirical Study”. Applied Linguistics 13 (2): 168-184.

Hall, K. and Scheiner, B. 1997. Übungsgrammatik DaF für Fortgeschrittene. 2nd ed. Ismaning: Verlag für Deutsch 
Helbig, G. 1993. „Wieviel Grammatik braucht der Mensch?”. In Wieviel Grammatik braucht der Mensch? Th. Harden, C. Marsh (ed.), 19-29. München: iudicium.

Helbig, G. and Buscha, J. 1986. Deutsche Grammatik. Ein Handbuch für den Ausländerunterricht. 11. ed. Leipzig.

Hulstijn, J.H. 1995. „Not all grammar rules are equal: Giving grammar instruction its proper place in foreign language teaching". In Attention, awareness in foreign language learning. R. Schmidt (ed.), 359-386. Manoa, HI: Second Language Teaching \& Curriculum Center.

Hulstijn, J.H. in press. „Towards a unified account of the representation, acquisition, and automatization of second-language knowledge". [to appear 2002 in a special edition of Second Language Research].

Hulstijn, J.H. and de Graaff, R. 1994. „Under what conditions does explicit knowledge of a second language facilitate the acquisition of implicit knowledge? A research proposal". In Consciousness and second language learning: Conceptual, methodological and [286] practical issues in language learning and teaching. J.H. Hulstijn and R. Schmidt (eds.), 97-112 (AILA Review 11).

Kempe, V. and MacWhinney, B. 1998. „The acquisition of case marking by adult learners of Russian and German". Studies in Second Language Acquisition 20: 543-587.

Köpcke, K.-M. 1998. „The acquisition of plural marking in English and German revisited: schemata versus rules". Journal of Child Language 25: 293-319.

Krashen, S.D. 1982. Principles and practice in second language acquisition. Oxford u.a.: Pergamon Press.

Krashen, S.D. 1985. The input hypothesis: Issues and Implications. New York: Longman.

Larsen-Freeman, D. and Long, M.H. 1991. An introduction to second language acquisition research. London: Longman.

Lima, S.D. and Corrigan, R.L. and Iverson, G.K. (ed.) 1994. The Reality of Linguistic Rules. Amsterdam and Philadelphia: Benjamins (Studies in Language Companion Series 26).

Mugdan, J. 1977. Flexionsmorphologie und Psycholinguistik. Tübingen: Narr.

Pienemann, M. 1989. „Is Language Teachable? Psycholinguistic Experiments and Hypotheses". Applied Linguistics 10: 83-113.

Pienemann, M. 1998. Language Processing and Second Language Development: Processability Theory. Amsterdam: Benjamins (Studies in Bilingualism 15).

Robinson, P. 1996. „Learning simple and complex second language rules under implicit, incidental, rule-search, and instructed conditions". Studies in Second Language Acquisition 18: 27-68.

Robinson, P. 1997. „Generalizability and automaticity of second language learning under implicit, incidental, enhanced, and instructed conditions". Studies in Second Language Acquisition 19, 223-248.

Seliger, H.W. 1979. „On the Nature and Function of Language Rules in Language Teaching”. TESOL Quarterly 13:3, 359-396.

Selinker, L. 1972. „Interlanguage”. IRAL 10:3, 209-221.

Serra Borneto, C. 2000. „Überlegungen zum Begriff 'Schwierigkeit' - Die Lernerperspektive”. In Sprachlehrforschung im Wandel. Beiträge zur Erforschung des Lehrens und Lernens von Fremdsprachen. Festschrift für Karl-Richard Bausch zum 60. Geburtstag. B. Helbig, K. Kleppin and F. Königs (eds.), 339-362. Tübingen: Stauffenburg.

Sharwood Smith, M. 1993. „Input enhancement in instructed SLA. Theoretical Bases”. Studies in Second Language Acquisition 15: 165-179. 
Sharwood Smith, M. 1994. „The unruly world of language”. In Implicit and explicit learning of language, N.C. Ellis (ed.), 33-44. San Diego, CA: Academic Press.

Swan, M. 1994. „Design criteria for pedagogic grammar rules”. In Grammar and the Second Language Classroom, M. Bygate, A. Tonkin and E. Williams (eds.), 45-55. Englewood Cliffs, N.J.: Prentice-Hall.

Vogel, K. and Vogel, S. 1975. Lernpsychologie und Fremdsprachenunterricht. Tübingen: Niemeyer (Romanistische Arbeitshefte 14).

Westney, P. 1994. „Rules and pedagogical grammar”. In Perspectives on Pedagogical Grammar. T. Odlin (ed.), 72-96. Cambridge: Cambridge UP.

Zimmermann, G. 1977. Grammatik im Fremdsprachenunterricht. Frankfurt/Main, Berlin and München: Diesterweg. 